\title{
Review of monitoring issues and technologies associated with the long-term underground storage of carbon dioxide
}

\author{
R. A. CHADWICK ${ }^{1}$, R. ARTS ${ }^{2}$, M. BENTHAM ${ }^{1}$, O. EIKEN ${ }^{3}$, S. HOLLOWAY ${ }^{1}$, \\ G.A. KIRBY ${ }^{1}$, J.M. PEARCE ${ }^{1}$, J.P. WILLIAMSON ${ }^{1}$, P. ZWEIGEL $^{3}$ \\ ${ }^{1}$ British Geological Survey, Kingsley Dunham Centre, Keyworth, Nottingham, NG12 \\ 5GG, United Kingdom. \\ ${ }^{2}$ Netherlands Institute of Applied Geoscience TNO - National Geological Survey, \\ Kriekenpitplein 18, PO Box 80015, 3508 TA Utrecht, The Netherlands. \\ ${ }^{3}$ Statoil Research Centre, Rotvoll, N-7005 Trondheim, Norway.
}

Corresponding author: R.A. Chadwick e-mail: rach@bgs.ac.uk

Words of text:

References:

Tables:

Figures:

\begin{abstract}
Large-scale underground storage of $\mathrm{CO}_{2}$ has the potential to play a key role in reducing global greenhouse gas emissions. Typical underground storage reservoirs would lie at depths of $1000 \mathrm{~m}$ or more and contain tens or even hundreds of millions of tonnes of $\mathrm{CO}_{2}$. A likely regulatory requirement is that storage sites would have to be monitored both to prove their efficacy in emissions reduction and to ensure site safety. A diverse portfolio of potential monitoring tools is available, some tried and tested in the oil industry, others as yet unproven. Shallow-focussed techniques are likely to be deployed to demonstrate short-term site performance and, in the longer term, to ensure early warning of potential surface leakage. Deeper focussed methods, notably time-lapse seismic, will be used to track $\mathrm{CO}_{2}$ migration in the subsurface, to assess reservoir performance and to calibrate/validate site performance simulation models. The duration of a monitoring programme is likely to be highly site specific, but conformance between predicted and observed site performance may form an acceptable basis for site closure.
\end{abstract}

[end of abstract]

To combat global warming and ocean acidification, effective control of greenhouse gas emissions is likely to prove one of the most important scientific and technological challenges of the $21^{\text {st }}$ Century. The Royal Commission on Environmental Pollution (2000) considered that atmospheric $\mathrm{CO}_{2}$ levels should not rise above 550 parts per million (ppm), but more recent work (Schellnhuber 2006) suggest that levels above $400 \mathrm{ppm}$ will have dangerous impacts. An equitable international agreement to keep $\mathrm{CO}_{2}$ levels in the atmosphere below even $550 \mathrm{ppm}$, based on emissions contraction 
and convergence by 2050, could require a reduction of UK annual carbon dioxide emissions of $60 \%$ by 2050 and possibly $80 \%$ by 2100 . These would be massive reductions (Metz et al. 2005). A promising technology to achieve these aims involves injecting industrial quantities of $\mathrm{CO}_{2}$ into underground storage reservoirs. Large-scale geological storage is currently being systematically monitored at three sites: Sleipner (North Sea), Weyburn (Canada) and In Salah (Algeria). It is clear that geological storage could make a significant impact on greenhouse gas emissions, perhaps acting as a bridging technology to ease the transition from current fossil fuel based energy systems to a future low- or zero-carbon energy system.

For $\mathrm{CO}_{2}$ storage to contribute to significant emissions reduction, it will have to be carried out on a very large scale. Total annual UK emissions for 2002 were estimated at $536 \mathrm{Mt} \mathrm{CO}_{2}$, of which the twenty largest power plants produced $119 \mathrm{Mt}$. A typical underground storage reservoir will need, therefore, to be capable of holding hundreds of millions of tonnes of $\mathrm{CO}_{2}$.

If underground $\mathrm{CO}_{2}$ storage is to become widely accepted, it has to be demonstrably effective from an emissions reduction standpoint and also to be demonstrably safe. Storage sites will, therefore, need to be monitored both to establish the current performance of the site and to constrain and calibrate predictions about its future behaviour (Benson et al. 2004, DTI 2005). This paper reviews some of the current technologies available for storage site monitoring, and some of the issues associated with tool deployment, such as complementarity. Examples from two ongoing $\mathrm{CO}_{2}$ storage operations are presented; emphasis is on the offshore storage site at Sleipner site, with additional onshore issues illustrated by reference to Weyburn. Costs, both relative and absolute, will clearly be an important driver in the selection of an overall monitoring strategy, but they are highly site-dependent, and not discussed in detail.

\section{Principles of Underground Storage}

$\mathrm{CO}_{2}$ can be injected into the pore spaces of an underground reservoir rock via one or more wells (Fig. 1), permeating the rock, and displacing some of the fluid (commonly saline water) that originally occupied the pore spaces. In basins around the UK, given likely injection depths in the range 1000 to $2000 \mathrm{~m}, \mathrm{CO}_{2}$ would typically be in a supercritical fluid phase, with a density of between 300 and $800 \mathrm{kgm}^{-3}$ (depending on geothermal gradient). The injected $\mathrm{CO}_{2}$ would, therefore, be buoyant, with a strong tendency to move upwards through the storage reservoir until it reaches a sealing barrier that prevents its further vertical migration. Horizontal or vertical permeability barriers, such as shale layers or faults, will impede movement within the reservoir and favour intra-reservoir trapping; lateral fluid pressure gradients will also play a part. Migration out of the reservoir would be facilitated by transmissive faults, caprock permeability or degraded wellbores (Fig.1).

For the purposes of describing the movement of $\mathrm{CO}_{2}$ in and around the primary storage reservoir it is convenient to define two distinct terms. Migration is here defined as movement of $\mathrm{CO}_{2}$ within the storage reservoir and the surrounding subsurface. Leakage is defined as transfer of $\mathrm{CO}_{2}$ from the geosphere either to the atmosphere at the land surface, or to seawater or to potable shallow aquifers. 
The amount of $\mathrm{CO}_{2}$ that can be injected into a particular reservoir will be limited by adverse processes, which can occur both in the short term, and also over much longer timescales, as the result of migration of the injected $\mathrm{CO}_{2}$. These include: an unacceptable rise in reservoir pressure, pollution of potable water by displacement of the saline/fresh groundwater interface, pollution of potable water by $\mathrm{CO}_{2}$ or toxic substances mobilised by $\mathrm{CO}_{2}$, escape of $\mathrm{CO}_{2}$ to the outcrop of a reservoir rock and escape of $\mathrm{CO}_{2}$ via a migration pathway through the caprock.

In the long term, the interaction of five principal mechanisms will determine the fate of $\mathrm{CO}_{2}$ in the reservoir: immobilisation in structural traps, immobilisation as a residual $\mathrm{CO}_{2}$ saturation, dissolution into the formation water, geochemical reaction with the formation water or rock-forming minerals and, if the seal is not perfect, migration out of the primary storage reservoir (e.g. Metz et al. 2005).

To design a monitoring programme to address migration and potential leakage over both the short term (the injection period) and long term, risk assessment is needed to determine a conceptual envelope of possible migration and leakage scenarios. Leaks may not necessarily occur directly above the storage site but will be strongly influenced by the local geological structure. For example, in the case of migration up gently dipping permeable strata, leaks may appear many kilometres from the storage site and the area needing to be covered by a monitoring programme may be much larger than the intended footprint of storage within the primary reservoir itself (Fig. 1). Leaks may also not occur for hundreds of years if the leakage path is long, but thereafter could be highly significant. In this respect, realistic long-term simulations of future site behaviour would be a pre-requisite for satisfactory site operation, monitoring and closure.

A comprehensive portfolio of tools is available for potential utilisation in storage site characterisation and monitoring (Fig. 2). Broadly speaking these can be categorised as deep-focussed tools for reservoir and overburden characterisation and monitoring $\mathrm{CO}_{2}$ migration, and shallow-focussed methods for overburden and surface characterisation, and the detection and measurement of surface leaks. A selection of the most promising tools is outlined below.

\section{Monitoring $\mathrm{CO}_{2}$ migration in the subsurface}

At the current time, monitoring $\mathrm{CO}_{2}$ migration in the subsurface relies on geophysical and well-based methods that have been developed over many years in the oil industry. In particular, geophysical time-lapse techniques, whereby repeated datasets are acquired over a period of time, have proved a powerful means of identifying and mapping subsurface changes, such as fluid movement. A brief account of some key geophysical tools is given below.

\section{Seismic methods}

Seismic techniques have a high imaging potential, most notably demonstrated at Sleipner (Fig. 3), but their performance varies significantly depending on reservoir 
depth, properties and pressure-temperature conditions (McKenna et al. 2003). As a general rule, reservoirs with good injection and storage characteristics (relatively unconsolidated with high porosity and permeability) will also tend to have suitable seismic properties for $\mathrm{CO}_{2}$ monitoring. Conversely, it will be more difficult to image $\mathrm{CO}_{2}$ stored within low porosity, low permeability reservoirs.

Surface 3D seismic data are ideally acquired over the full volume of the reservoir and overburden, and offer the potential to quantify total amounts of $\mathrm{CO}_{2}$ in the reservoir and also to identify migration from the storage reservoir into and through the overburden. Direct quantification of $\mathrm{CO}_{2}$ volumes in the reservoir can, at least in principle, be achieved through the analysis of reflection amplitudes and the amount and distribution of velocity 'pushdown' (the acoustic 'shadow' cast by the plume on underlying reflections). Quantitative analysis however is a challenging problem due to a number of significant uncertainties, well illustrated by the Sleipner case (see below). Migration of $\mathrm{CO}_{2}$ upwards through the overburden, particularly in the gas phase, can be detectable on seismic data via the generation of 'bright spots'; distinct high amplitude reflections of localised extent caused by the sharp decrease in acoustic impedance within rocks saturated by $\mathrm{CO}_{2}$.

Detection of $\mathrm{CO}_{2}$ in the overburden, as 'bright spots', can potentially be used to estimate migration fluxes. To be detectable a $\mathrm{CO}_{2}$ accumulation must have lateral and vertical dimensions sufficient to produce a discernible seismic response. A study by Myer et al. (2002) based on theoretical resolution considerations, has suggested that $\mathrm{CO}_{2}$ accumulations as small as 10000 to 20000 tonnes should be detectable under favourable conditions. Results from the Sleipner time-lapse surveys (see below) indicate that these figures may be somewhat conservative. Repeatability noise (which depends on the accuracy with which successive surveys can be matched), rather than resolution, may be the key parameter controlling detection thresholds.

Wellbore seismic methods, such as VSP and cross-hole seismics, provide higher resolution of the near-borehole environment with direct measurement of velocity and signal attenuation (both key indicators of fluid saturation) providing finer-scale information complementary to the surface methods. VSPs provide specific detail around the wellbore such as the early detection of $\mathrm{CO}_{2}$ migration outside the casing. Cross-hole seismic requires at least two wells through or close to the storage reservoir. Changes in travel-time and signal amplitude between the wells can be used to map velocity and attenuation variations in the section between the wells that relate to $\mathrm{CO}_{2}$ saturations and/or pressure changes. Recent practical experience from the Nagaoka $\mathrm{CO}_{2}$ injection experiment (Kikuta et al. 2005) indicates that amounts of $\mathrm{CO}_{2}$ as small as hundreds of tonnes can be detectable using the crosshole method.

Multicomponent (MC) seismic methods record both the compressional (P-wave) and shear (S-wave) components of ground motion. The latter are more sensitive than the former to fractures or microfractures, but much less sensitive to the fluid content. By analysing combined P- and S-wave signals, it is possible to obtain a more complete picture of fluid behaviour, including improved discrimination of fluid pressure and saturation changes and better imaging beneath gas accumulations. In particular, changes may be observable in low permeability overburden sequences where the lack of discrete $\mathrm{CO}_{2}$ accumulations may render conventional seismic ineffective. Notable examples of the successful deployment of $\mathrm{MC}$ seismic include the $\mathrm{CO}_{2}$-Enhanced oil 
recovery (EOR) operation at the Vacuum Field in Texas (Angerer et al. 2001) and more recently, at Weyburn (Wilson \& Monea 2004). MC seismic is, however, considerably more expensive than conventional seismic and shear-wave data collection presents additional difficulties offshore.

\section{Gravimetric methods}

Gravimetry measures the gravitational acceleration due to mass distributions within the earth to detect variations in subsurface rock or fluid density. The possibility of monitoring injected $\mathrm{CO}_{2}$ with repeated gravity measurements is strongly dependent on $\mathrm{CO}_{2}$ density and subsurface distribution. In general terms the size of the gravity change gives information on subsurface volumes and densities, while the spatial variation in gravity gives information on lateral $\mathrm{CO}_{2}$ distribution. The weakest aspect of the gravity data is in resolving absolute depth information on the $\mathrm{CO}_{2}$ accumulation.

Although of much lower spatial resolution than the seismic methods, gravimetry offers some important complementary adjuncts to time-lapse seismic monitoring. Firstly, it can provide independent verification of the change in subsurface mass during injection via Gauss's Theorem. This may enable estimates to be made of the amount of $\mathrm{CO}_{2}$ going into solution, an important uncertainty in efforts to quantify free $\mathrm{CO}_{2}$ in the reservoir (dissolved $\mathrm{CO}_{2}$ is effectively invisible on seismic data). Dissolution, moreover, is an important long-term trapping process, difficult to quantify accurately through flow simulations. Secondly, deployed periodically, gravimetry could be used as an 'early warning system' to detect the accumulation of migrating $\mathrm{CO}_{2}$ in shallow overburden traps where it is likely to be in the low density gaseous phase with a correspondingly strong gravity signature.

The detection limits of gravimetry are highly site specific and depend on very high resolution levelling. Low $\mathrm{CO}_{2}$ density and a spatially confined $\mathrm{CO}_{2}$ bubble will give the largest gravity change for a given mass, shallow depths and high temperatures favouring lower densities. Recent work at Sleipner (see below) suggests that measurement accuracy for repeat surveys offshore may be as low as 3 to $5 \mu \mathrm{Gal}$. Land gravimetry is likely to have a similar accuracy. At these repeatability levels, under favourable conditions, accumulations of $\mathrm{CO}_{2}$ in the gaseous state of less than $1 \mathrm{Mt}$ may be detectable at depths around $500 \mathrm{~m}$ (Fig. 4). Such a figure seems quite large, but in the context of a possible future large-scale storage site, would be less than $1 \%$ of the total amount stored. For general mass verifications within a reasonably shallow storage reservoir, injected $\mathrm{CO}_{2}$ masses of more than about $2 \mathrm{Mt}$ would be expected to produce a detectable response.

\section{Electromagnetic methods}

In a similar way to gravimetry, electromagnetic (EM) methods offer the potential for low resolution, low-cost, site monitoring. EM techniques deploy time-variant source electrical fields to induce secondary electrical and magnetic fields that carry information about subsurface electrical structure. $\mathrm{CO}_{2}$ is resistive, so EM methods are 
likely to be suitable for monitoring storage in saline formations where $\mathrm{CO}_{2}$ is displacing more conductive formation waters.

Recent developments of offshore controlled source EM systems (so-called seabedlogging) can detect thin resistive anomalies at depths up to several kilometres. Recent surveys have successfully determined the presence and absence of hydrocarbons within reservoirs (Johansen et al. 2005). Direct detection of resistive $\mathrm{CO}_{2}$ zones within more conductive water-filled strata should, therefore, also be possible. So far, seabed logging has been restricted to quite deep waters $(>300 \mathrm{~m})$ as airwave interference made getting satisfactory results in shallow water difficult. Recent developments indicate that these technical difficulties are being overcome.

Cross-hole EM is comparable to cross-hole seismics in that transmitters and receivers are placed in adjacent boreholes and tomography is used to map the conductivity structure of the section between the wells. The technique is particularly useful when used in conjunction with seismic methods, providing complementary information to reduce uncertainty. Cross-hole EM imaging experiments in the United States were successful in monitoring $\mathrm{CO}_{2}$ migration in an enhanced oil recovery (EOR) flood (Hoversten et al. 2002). It is fair to say, however, that the electrical properties of $\mathrm{CO}_{2}$ distributed in subsurface reservoirs are not fully understood. Significant further research is required before the efficacy of the electrical methods can be fully assessed.

\section{Monitoring $\mathrm{CO}_{2}$ leakage}

Monitoring for $\mathrm{CO}_{2}$ leakage involves the detection or measurement of $\mathrm{CO}_{2}$ in the overburden above the caprock and either in the soil or in the air, or, offshore, in the seabed or the water column. Unlike the deep-focussed technologies, shallow monitoring for leakage would not be expected to actually detect leaking $\mathrm{CO}_{2}$ at a well-designed storage site in the foreseeable future. Current research emphasis therefore is on methodologies for establishing secure baseline conditions, developing tools and strategies for the robust detection and measurements of leaks should they occur in the future, and testing tools at naturally-ocurring $\mathrm{CO}_{2}$ seep sites..

A key aspect of leakage monitoring is the ability to obtain robust measurements of leakage flux over wide areas. There is something of a conflict here, in that methods which can readily be deployed over large areas tend to provide only qualitative information on $\mathrm{CO}_{2}$ fluxes, whereas tools capable of accurate measurement tend to be only applicable to very restricted sites. A comprehensive leakage monitoring programme therefore, will have to deploy complementary methods in combination.

Technologies for the direct measurement of $\mathrm{CO}_{2}$ leakage offshore are very much in their infancy. Seabed sampling systems are under development, a key requirement being that fluid within the sample chamber is maintained at seafloor pressure, allowing fluid subsamples to be withdrawn for a number of analytical techniques without degassing the remaining fluid. Onshore, there is a wide range of established techniques for the detection and measurement of $\mathrm{CO}_{2}$ and other gases in spring and well waters, and in the soil. These can be used to establish pre-storage baseline conditions and also, by detecting naturally-occurring seepages, to indicate potential migration and leakage pathways. 


\section{Acoustic imaging and sonar bathymetry}

Indirect methods can provide important shallow monitoring information over large areas above storage sites. Offshore, acoustic imaging can provide very high resolution images of the seafloor and the shallow sub-seafloor, perhaps resolving features more than an order of magnitude smaller than conventional seismic reflection data. They offer the capability of imaging gas escape structures at the seabed such as pockmarks (Fig. 5a) and even free gas in the water column itself (Fig. 5b). Naturally occurring pockmarks and shallow gas chimneys (due to methane escape) may act as preferential pathways for future $\mathrm{CO}_{2}$ seepage and may therefore be used to optimise the deployment of dedicated gas measurement equipment.

\section{Soil gas methods}

Ambient levels of $\mathrm{CO}_{2}$ in soils are many times greater than concentrations in the air. Welles et al. (2001) quote typical soil gas $\mathrm{CO}_{2}$ concentrations of 2000-10000 ppm, The equipment needed for soil gas surveying ranges from fixed accumulation chambers to small portable systems comprising sampling and analysis equipment. In the latter case, probes or accumulation chambers are placed in a grid configuration over the expected leakage 'footprint', in or on the soil, and samples analysed periodically to determine soil gas composition and fluxes. A key issue in soil gas surveying is to establish accurate baseline conditions by identifying and removing the effect of seasonal variations. A clear requirement therefore is to have a robust understanding of climate and seasonal changes in soil use and processes for the site. This is exemplified by the Weyburn soil gas monitoring programme (see below).

\section{Atmospheric measurement}

Most techniques for the measurement of atmospheric $\mathrm{CO}_{2}$ rely on the absorption of infrared radiation, and range from large, ground-based instruments, to small and portable tools that can be mounted on a vehicle or in an aircraft. There are two basic types: non-dispersive infrared gas analyzers and infrared diode laser instruments. The former use a broad-spectrum source in a small closed chamber containing the sample to be analyzed - a 'short closed-path' technique. Infrared diode laser instruments can be used in closed-path mode, but also for 'open-path' techniques where the free atmosphere is analyzed. They can be deployed over either a short (less than $2 \mathrm{~m}$ ) or long path length (hundreds of metres), with results averaging the concentrations over these distances. The eddy covariance (or correlation) micrometeorological method (Miles et al. 2004) essentially consists of an infrared gas analyzer mounted on a tower alongside a sensitive sonic anemometer to measure wind speed and direction. The detector is basically very similar to those described above, and is able to detect $\mathrm{CO}_{2}$ from an area ('footprint') upwind. The size and the shape of the footprint is derived mathematically from the wind speed and direction. By combining $\mathrm{CO}_{2}$ concentration data with meteorological information, eddy covariance can produce $\mathrm{CO}_{2}$ flux data, expressed as the amount of $\mathrm{CO}_{2}$ released per unit area per unit time and is particularly appropriate in more open terrain. A weakness of the eddy covariance technique is its 
propensity to detect other anthropogenic sources of $\mathrm{CO}_{2}$ (vehicles, industrial plant etc), as well as natural variations (diurnal, seasonal etc). These have to be carefully characterised so their effects can be removed.

\section{Remote sensing}

Remote sensing (airborne and satellite) methods are mainly suitable for detecting changes in floral cover due to the effects of $\mathrm{CO}_{2}$. The use of airborne hyperspectral imaging for mapping floral habitats is well established, for example surveys over the Rangely $\mathrm{CO}_{2}$-EOR field have suggested that surface seepages are minimal (Pickles \& Cover 2004). A more innovative approach is to use the method for direct detection of $\mathrm{CO}_{2}$ by utilizing absorption features that fall within the wavelength range of airborne hyperspectral scanners (e.g. Goff et al. 2001 and Mori et al. 2001). Imaging of leaks from natural gas storage facilities (REFERENCE) has proved the efficacy of the method, which could be potentially extended to $\mathrm{CO}_{2}$ detection. Methodological testing and calibration is required to establish if the smaller concentrations likely to be associated with leaks from $\mathrm{CO}_{2}$ storage facilities could be detected against the more complex and variable backdrop of the natural environment.

Airborne EM techniques have been used to detect conductivity anomalies associated with hydrogeochemical changes in ground water, which are caused by pollution plumes derived from overlying mineral spoil heaps. The method could potentially detect changes in shallow ( $<100 \mathrm{~m}$ depth) groundwater resistivity due to the presence of dissolved $\mathrm{CO}_{2}$.

\section{Example of monitoring $\mathrm{CO}_{2}$ migration in the subsurface - Sleipner}

The $\mathrm{CO}_{2}$ injection operation at the Sleipner gas field in the North Sea (Baklid et al. 1996), operated by Statoil and partners, is the world's first industrial-scale $\mathrm{CO}_{2}$ injection project aimed at greenhouse gas mitigation (specifically to avoid Norwegian carbon tax). $\mathrm{CO}_{2}$ separated from natural gas produced at Sleipner is currently being injected at a depth of just over $1000 \mathrm{~m}$ into the Utsira Sand, a major saline aquifer. Injection started in 1996 and is planned to continue for about twenty years, at a rate of about one million tonnes per year. The $\mathrm{CO}_{2}$ plume is currently being monitored by time-lapse seismic and gravimetric methods.

\section{Imaging $\mathrm{CO}_{2}$ migration}

Time-lapse 3D seismic data were acquired in 1994, prior to injection, and again in 1999, 2001 and 2002, with respectively 2.35, 4.26 and $4.97 \mathrm{Mt}$ of $\mathrm{CO}_{2}$ in the reservoir. Full details of current interpretive work on the seismic datasets are given in Arts et al. (2004a, b) and Chadwick et al. (2004, 2005). Suffice to say here that the $\mathrm{CO}_{2}$ plume is imaged as a number of bright sub-horizontal reflections within the reservoir, growing with time (Fig. 6a). The reflections are interpreted as arising from thin ( $<8 \mathrm{~m}$ thick) layers of $\mathrm{CO}_{2}$ trapped beneath thin intra-reservoir mudstones and the reservoir caprock. The plume is roughly $200 \mathrm{~m}$ high and elliptical in plan, with a major axis increasing from about $1500 \mathrm{~m}$ in 1999 to about $2000 \mathrm{~m}$ in 2001 (Fig. 6b). 
The plume is underlain by a prominent velocity pushdown, a downward relative displacement of reflectors (Fig. 7), caused by the seismic waves travelling much more slowly through $\mathrm{CO}_{2}$-saturated rock than through the virgin aquifer.

\section{History-matching and quantification}

History-matched reservoir flow simulations of plume development at Sleipner produce a reasonable fit to the observed data. For example, individual $\mathrm{CO}_{2}$ layers observed on the seismic can be reproduced in the flow simulations (Lindeberg et al. 2001) and synthetic seismic models based on the flow simulations show reasonable agreement with the observed data (Fig. 8; Arts et al. 2005). Significant uncertainty remains however, regarding the detailed geometry of plume layering and, in particular, the nature of $\mathrm{CO}_{2}$ - water mixing at low saturations (see below), which precludes accurate simulation of velocity pushdown.

Inverse modelling based upon quantifying amounts of $\mathrm{CO}_{2}$ from layer reflectivity and velocity pushdown has been used in an attempt to verify the in situ injected mass of $\mathrm{CO}_{2}$. Modelling assumed that plume reflectivity largely comprises tuned responses from thin layers containing high levels of $\mathrm{CO}_{2}$ whose thickness varies directly with reflection amplitude. Calculated models comprise thin layers containing high saturation $\mathrm{CO}_{2}$, mapped according to an amplitude-thickness tuning relationship. Between the layers, a lesser component of much lower saturation $\mathrm{CO}_{2}$ is required to match the observed pushdown.

A key uncertainty at Sleipner is formation temperature. A poorly constrained measurement of $36^{\circ} \mathrm{C}$ is available for the Utsira reservoir, but regional temperature patterns suggest that the reservoir may be several degrees warmer. At the higher temperatures, $\mathrm{CO}_{2}$ would have markedly different physical properties, with a significantly lower density and bulk modulus. The principal effect of lowering density would be a correspondingly larger in situ volume of $\mathrm{CO}_{2}$; a secondary, but still important, effect of higher reservoir temperatures would be to give significantly lower seismic velocities. Both effects would impact crucially on any quantitative analysis of the seismic data.

Inverse models of $\mathrm{CO}_{2}$ distribution in the 1999 plume have been generated, based on both the measured, and a possible higher, temperature scenario. The distribution of $\mathrm{CO}_{2}$ in both models is consistent with the known injected mass (allowing for parameter uncertainty) and both models can replicate the observed plume reflectivity and the observed velocity pushdown (Fig. 9). However, the higher temperature model requires that the dispersed (low-saturation) component of $\mathrm{CO}_{2}$ has significantly higher seismic velocities than is required for the lower temperature model. This implies that the dispersed $\mathrm{CO}_{2}$ has a somewhat patchy distribution, with heterogeneous mixing of the $\mathrm{CO}_{2}$ and water phases (Sengupta \& Mavko 2003). This highlights a key uncertainty in verification estimates, the velocity behaviour of the $\mathrm{CO}_{2}$-water-rock system, which is heavily dependent on the (poorly-constrained) nature of small-scale mixing processes between the fluid phases (Mavko \& Mukerji 1998). Because of these uncertainties, a modelling solution that uniquely verifies the injected volume has not yet been obtained. 


\section{Migration detection}

The potential capability of the Sleipner seismic data to detect the migration of small quantities of $\mathrm{CO}_{2}$ can be illustrated by examining the topmost part of the 1999 plume, which is marked by two small $\mathrm{CO}_{2}$ accumulations trapped directly beneath the caprock (Fig. 10). From the reflection amplitudes the net volumes of the two accumulations can be estimated at 9000 and $11500 \mathrm{~m}^{3}$ respectively. Other seismic features on the timeslice can be attributed to repeatability noise, arising from intrinsic minor mismatches of the 1999 and 1994 (baseline) surveys. It is clear that the level of repeatability noise plays a key role in determining the detectability threshold. Thus for a patch of $\mathrm{CO}_{2}$ to be identified on the data it should be possible to discriminate unequivocally between it and the largest noise peaks. Preliminary analysis suggests that accumulations larger than about $4000 \mathrm{~m}^{3}$ should fulfil this criterion. Assuming high saturations, this would correspond to about 1600 tonnes of $\mathrm{CO}_{2}$ at the top of the reservoir where $\mathrm{CO}_{2}$ has a density of about $400 \mathrm{~kg} \mathrm{~m}^{-3}$, but less than 600 tonnes at 500 $\mathrm{m}$ depth, where the density is considerably lower (detectable mass would be further lowered for $\mathrm{CO}_{2}$ at lower saturations). Actual detection capability however depends crucially on the nature of the $\mathrm{CO}_{2}$ accumulation. Small thick accumulations in porous strata would tend to be readily detectable, whereas distributed leakage through low permeability strata may be difficult to detect with conventional seismic techniques. Similarly, leakage along a fault within low permeability rocks would be difficult to detect. It could be argued however that faults within low permeability strata are, in any case, unlikely to provide effective fluid pathways.

\section{Gravimetry}

A seabed gravity survey was acquired at Sleipner in 2002 (Nooner et al. 2006), with $4.97 \mathrm{Mt}$ of $\mathrm{CO}_{2}$ injected, and a repeat survey in 2005 with $7.75 \mathrm{Mt}$ of $\mathrm{CO}_{2}$ injected (an additional $2.78 \mathrm{Mt}$ ). The surveys were based around pre-positioned concrete benchmarks on the seafloor that served as reference locations for the (repeated) gravity measurements. Relative gravity and water pressure readings were taken at each benchmark by a customised gravimetry and pressure measurement module mounted on a Remotely Operated Vehicle (Fig. 11a). Thirty concrete benchmarked survey stations were deployed in two perpendicular lines, spanning an area of about 7 $\mathrm{km}$ east-west and $3 \mathrm{~km}$ north-south and overlapping the subsurface footprint of the $\mathrm{CO}_{2}$ plume (Fig. 11b). Each survey station was visited at least three times to better constrain instrument drift and other errors, resulting in a single station repeatability of about $4 \mu \mathrm{Gal}$. For time-lapse measurements an additional uncertainty of $1-2 \mu \mathrm{Gal}$ is associated with the reference null level. The final detection threshold for Sleipner therefore is estimated at about $5 \mu \mathrm{Gal}$.

The time-lapse gravimetric response due to $\mathrm{CO}_{2}$ was obtained by removing the modelled gravimetric time-lapse response from the Sleipner East field (the deeper gas reservoir currently in production) from the measured gravity changes between 2002 and 2005.

Forward modelling was then performed (Nooner et al. 2006) to investigate whether the gravity changes between 2002 and 2005 could provide an indication of the in situ 
$\mathrm{CO}_{2}$ density. This was done via plume models constrained both by time-lapse seismic data (using generalised plume distributions based on the 2001 3D survey) and also by reservoir flow models. The best fit was obtained for the higher temperature seismically-constrained model. Statistical analysis indicates that the average $\mathrm{CO}_{2}$ density in the plume is around $530 \mathrm{kgm}^{-3}$. This is consistent with reservoir temperatures towards the high end of the uncertainty range.

It is clear from this example that the gravimetry survey has provided valuable independent information capable of reducing uncertainty in the seismic analysis. The use of complementary methodologies in this way can be very effective in an integrated monitoring programme.

\section{Example of monitoring for surface leakage - Weyburn}

The Weyburn operation in Saskatchewan, Canada (Wilson \& Monea 2004), is principally an EOR project, but with the secondary aim of ultimately storing $20 \mathrm{Mt}$ of anthropogenic $\mathrm{CO}_{2}$. Injection started in late 2000, using $\mathrm{CO}_{2}$ captured from a coal gasification plant in North Dakota and transported to the site via a $320 \mathrm{~km}$ pipeline. $\mathrm{CO}_{2}$ is injected at rates of between one and two million tonnes per year, into a thin, carbonate reservoir at a depth of about $1500 \mathrm{~m}$. Weyburn differs from Sleipner in having a large number of wells, both active and abandoned, which penetrate the storage reservoir.

The shallow monitoring programme at Weyburn provides a field example of a generic monitoring methodology that could be applied at future onshore storage sites or around onshore transport infrastructure. A full account of the Weyburn shallow monitoring work is given in Riding \& Rochelle (this volume), here we shall just summarise those key findings pertinent to this paper.

Baseline surveys were acquired in 2001 to evaluate natural variation (principally seasonal effects), in soil gas concentration and to identify sites of higher gas flux that may be indicative of deep gas escape (e.g. Strutt et al. 2003). Measurements included gas concentrations in the shallow unsaturated soil horizon (soil gas); mass transfer rates of $\mathrm{CO}_{2}$ across the soil-atmosphere interface (gas flux) and long-term monitoring of radon flow rates, as a proxy for $\mathrm{CO}_{2}$, using probes buried for up to a year at $2 \mathrm{~m}$ depths.

Soil gas monitoring of $\mathrm{CH}_{4}, \mathrm{CO}_{2}, \mathrm{CO}_{2}$ flux, $\mathrm{O}_{2},{ }^{222} \mathrm{Rn}$ and thoron (via ${ }^{220} \mathrm{Rn}$ ) was carried out on a 360 point grid at $200 \mathrm{~m}$ spacing, with points extending to the southwest of the initial injection area. Soil gas samples were also analysed in the laboratory for $\mathrm{He}$, light hydrocarbons, $\mathrm{N}_{2}, \mathrm{O}_{2}$ and $\mathrm{S}$. Follow-up surveys in the autumn of 2002 traversed anomalies seen on the earlier grid survey. Selected $\mathrm{CO}_{2}$ and radon anomalies on these profiles were investigated in more detail for signs of natural pathways for deep gas escape, using $\mathrm{He}, \mathrm{CH}_{4}$ and $\mathrm{Rn}$ as proxies for potential future $\mathrm{CO}_{2}$ escape. Continuous radon monitoring probes were installed at sites where He and radon data, in particular, indicated the potential for deep gas migration. Surveys of the sampling grid, and most of the more detailed profiles, were repeated in the autumns of 2002 and 2003. The radon monitoring probes were in operation virtually continuously from the autumn of 2001 through to 2004. 
Marked changes were seen in $\mathrm{CO}_{2}$ concentration and surface flux levels between each of the three datasets (Riding \& Richelle Fig. 21, this volume). Higher values marked the growing season of July 2001, with lower levels in autumn 2002 and further reduction in autumn 2003, when conditions were cooler and the growing season almost over. These results illustrate the importance of shallow biological reactions that produce $\mathrm{CO}_{2}$ as a metabolic by-product. In contrast, the radon and thoron data were found to be similar for the three years, implying that both these gases have a shallow in-situ origin. Some of the $\mathrm{CO}_{2}$ anomalies, based on initial air-photo interpretation, may represent the surface expression of deep faults, but soil gas data indicated that the elevated values in these areas are more likely due to shallow biological reactions in the moist, organic-rich soil. Stable isotopic analyses may help identify the sources of $\mathrm{CO}_{2}$, potentially distinguishing near-surface biogenic $\mathrm{CO}_{2}$ from deeper injected $\mathrm{CO}_{2}$, if isotopic values were sufficiently distinct. There was no clear correspondence between soil gas $\mathrm{CO}_{2}$ anomalies and the location of the $\mathrm{CO}_{2}$ injection wells.

The temporal variation of $\mathrm{CH}_{4}$ was significantly different from the $\mathrm{CO}_{2}$ with only a very slight increase over the same period. This trend may be due to the seasonal drying of the soil and subsequent increase in soil permeability to air, resulting in the greater downward diffusion of air with its constant methane concentration of about $2.5 \mathrm{ppm}$. The correlation between soil gas $\mathrm{CO}_{2}$ and $\mathrm{CH}_{4}$ is low because they are produced via different metabolic pathways.

The distribution of radon and thoron anomalies lacked any clear linear trends that might indicate the presence of a gas-permeable fault or fracture system. Continuous profiling by gamma spectrometry did not indicate any marked anomalies in uranium or thoron series radionuclides that might be linked to radon escape through a fault or fracture system.

An inverse linear relationship was observed between concentrations of $\mathrm{CO}_{2}$ and $\mathrm{O}_{2}$, whereas $\mathrm{N}_{2}$ remained essentially constant (Riding \& Rochelle this volume), providing further strong evidence of a biogenic origin for the $\mathrm{CO}_{2}$ via reactions in which $\mathrm{O}_{2}$ is consumed. If significant migration of $\mathrm{CO}_{2}$ from depth were occurring, both $\mathrm{O}_{2}$ and $\mathrm{N}_{2}$ would be diluted as $\mathrm{CO}_{2}$ levels increased, similar to areas of natural deep $\mathrm{CO}_{2}$ escape, such as Cava dei Selci in Italy (Riding \& Rochelle this volume). The isotopic values of three soil gas samples collected in summer 2001, all indicated that the soil gas $\mathrm{CO}_{2}$ was produced by microbial or root metabolism of organic matter from local plants. However, it is difficult to draw firm conclusions from this small number of samples.

Borehole integrity was investigated by measuring soil gas around two decommissioned oil wells, one abandoned and the other suspended due to failed casing. The well with failed casing had weakly anomalous $\mathrm{CO}_{2}$ at two sites but this was not the case for other gases. The abandoned well had normal background $\mathrm{CO}_{2}$ values. Statistical populations of $\mathrm{CO}_{2}$ and radon were generally higher for the suspended well while those for $\mathrm{CH}_{4}$ and $\mathrm{C}_{2} \mathrm{H}_{6}$ were higher for the abandoned well, compared to background values, although all individual values lay well within the range observed across the site. There was one He anomaly at the abandoned well site, but the lack of correspondence between anomalies of different gases suggests that current leakage from depth in the well is insignificant. 
Electronic radon sensors were installed up to $1.9 \mathrm{~m}$ deep at six sites selected from the detailed soil gas profiles located across radon and $\mathrm{CO}_{2}$ anomalies. Hourly measurements of radon concentration, temperature and atmospheric pressure showed seasonal variations in radon concentration, which were modelled against atmospheric parameters, indicating the importance of pressure, rainfall and temperature on gas migration. In addition, $\mathrm{CO}_{2}$ fluxes deeper in the soil were calculated and compared to surface rates. Ultimately, the probes may detect the first precursors of any possible $\mathrm{CO}_{2}$ escape to the surface. Data from the probes showed seasonal variations in the gas flow regime and in soil permeability. Maximum gas velocities were in the range 5-15 $\mathrm{cm} \mathrm{h}^{-1}$, values typical of faults, while background values reflected diffusive gas transport. Carbon dioxide fluxes at $2 \mathrm{~m}$ depth were calculated to be 10-20 times lower than those at surface. This is consistent with declining biogenic $\mathrm{CO}_{2}$ production with depth and suggests it may be better to monitor flux at this depth where biogenic influences are muted.

\section{Site performance and monitoring detection capability}

The principal requirements of a site monitoring programme are to establish current storage site performance and to assist in the prediction of future performance, with the ultimate aim of enabling site closure (Pearce et al. 2006). It is clear that site performance in terms of safety is not necessarily synonymous with performance in terms of emissions reduction. Thus, a site leaking low fluxes of $\mathrm{CO}_{2}$ over a wide area may fail a total emissions mitigation criterion, but could well be perfectly safe. Conversely, a site may have a single localised small leak that is well beneath an approved total emissions threshold, but which gives rise to a locally hazardous leakage flux at the surface.

In fact, the basic aspiration for geological storage is zero leakage. In other words, a properly characterised storage site would be expected to store $\mathrm{CO}_{2}$ indefinitely with no loss to atmosphere or seawater. Nevertheless, it is possible that a proportion of sites may leak in due course, with leakage perhaps of a localised and/or erratic nature. Other sites will employ multiple reservoir and/or multiple barrier storage concepts where significant subsurface migration of $\mathrm{CO}_{2}$ is part of the storage plan.

Monitoring-based verification of site containment performance could, therefore, follow a number of approaches: direct tracking and/or quantification of $\mathrm{CO}_{2}$ in the reservoir; reliable detection and quantification of subsurface migration out of the primary reservoir (including via engineered components such as wells) and robust measurement of fluxes at the surface.

The utility of setting site performance thresholds is currently an issue of much debate in regulatory circles. Setting aside for the time being issues of local health and safety (see below), a logical way of establishing satisfactory containment performance in terms of emissions reduction could be to estimate how well a nominal storage site should perform in order to fulfil its basic emissions reduction function. Lindeberg (2003) showed how different storage retention times were related to future stabilised atmospheric concentrations - sites retaining $\mathrm{CO}_{2}$ for several thousand years (or longer) can be considered as providing effective mitigation. In a simpler treatment, 
Hepple \& Benson (2003) have calculated global site leakage rates consistent with atmospheric stabilisation targets of 350, 450, 550, 650 and 750 ppm (Table 1). This was done by calculating the difference between six possible future $\mathrm{CO}_{2}$ emissions scenarios as proposed by the Intergovernmental Panel on Climate Change (IPCC) (Nakicenovic \& Swart 2000) and the emissions consistent with meeting a range of long-term atmospheric $\mathrm{CO}_{2}$ stabilization targets (Wigley et al. 1996). By assuming that the amount of leakage is proportional to the amount of $\mathrm{CO}_{2}$ stored at any given time, acceptable annual site leakage rates can be calculated. Although simplistic, this approach forms a credible basis for a preliminary treatment of the problem. Thus, according to Hepple \& Benson, stabilization at any atmospheric $\mathrm{CO}_{2}$ level less than $550 \mathrm{ppm}$ would require annual leakage rates to be less than $0.01 \%$ for all IPCC emission scenarios.

The question arises therefore as to what extent could a monitoring programme be able to demonstrate that a storage site emissions are below a given threshold.

\section{Subsurface monitoring}

Deep monitoring technologies do not measure surface leakage explicitly, so cannot provide a direct indication of site emissions performance. However the ability to reliably detect small fluxes of $\mathrm{CO}_{2}$ migrating out of the primary storage reservoir can place a useful upper bound on any consequent surface leakage, and, perhaps more importantly, can provide powerful insights into current and future containment processes.

At Sleipner, the seismic data is yielding a nominal detection limit of around 1600 tonnes of $\mathrm{CO}_{2}$ at the top of the reservoir (see above). No migration from the primary reservoir has so far been detected on any of the time-lapse datasets up to and including the 2002 survey. Following Hepple \& Benson (2003), whereby supposed migration fluxes would be proportional to the amount of $\mathrm{CO}_{2}$ stored, the absence of detectable migration at Sleipner by 2002 is consistent with a migration rate of less than $0.02 \%$ per annum. Clearly, the longer that migration out of the reservoir remains demonstrably undetectable, the tighter the rates that can be constrained. This approach however does not take into account the possibility that several undetected smaller amounts of $\mathrm{CO}_{2}$ may be migrating from more than one point in the reservoir. On the plus side, as intimated above, detection of migration from the primary reservoir is an inherently conservative performance measure, as this will generally significantly exceed any subsequent leakage, due to other trapping processes that operate on $\mathrm{CO}_{2}$ as it migrates to the surface.

In principle therefore, seismic monitoring can provide the type of information required for performance verification. Considerable caution must be exercised in applying this principle however. As expanded above, the fact that a seismic detection limit can be determined does not necessarily mean that migration can be reliably quantified. If migrated $\mathrm{CO}_{2}$ does not accumulate in a suitable trap it may remain undetectable as a seismic reflection (although velocity pushdown may well produce a detectable time-lapse signal depending on the reflectivity of the geology). In this case, other monitoring techniques with different detection requirements may help in leakage assessment (e.g. downhole pressure in either the target reservoir or overlying aquifers). Irrespective of what particular tools are deployed, the detection and 
quantification of small $\mathrm{CO}_{2}$ fluxes in the subsurface remains technically very challenging and ultimate monitoring capabilities in this regard are likely to be highly site specific.

\section{Surface monitoring}

In principle, surface monitoring can provide a direct measurement of site leakage. However, robust surface monitoring is likely to be practicable at onshore sites only. Offshore, acoustic seabed imaging and local sediment or seawater sampling may be utilised but reliable quantification of shallow fluxes over extended areas is unlikely to be a practical proposition in the near future. A further consideration is that a properly selected storage site is unlikely to result in leakage to surface in the near future, so measurable fluxes are unlikely to occur. So, whilst surface monitoring datasets can verify current site performance, more generally they will have to be used in a predictive manner to indicate the possibility of future surface leakage, for example through identification of potential leakage pathways and their impacts. Surface monitoring will also require very well defined baselines, against which future $\mathrm{CO}_{2}$ concentrations and fluxes can be compared. This, in itself, poses challenges, especially considering the likely decadal timescales of projects and variable nature of ecosystems, which control baseline conditions over these timeframes. Once baseline surface monitoring has been completed, subsequent monitoring at the surface may only be required if deep monitoring indicates leakage may occur

Turning to health and safety issues, surface $\mathrm{CO}_{2}$ flux measurements are currently available for a number of sites, mostly naturally-occurring, where $\mathrm{CO}_{2}$ is leaking to the surface at the present day (Table 2). These provide valuable insights into the circumstances surrounding the buildup of potentially hazardous accumulations, and the likelihood of these actually occurring.

Natural $\mathrm{CO}_{2}$ emissions are found in large provinces such as the French carbo-gaseous province (Czernichowski-Lauriol personal communication), the Paradox Basin (Shipton et al. 2005) or the Yellowstone hydrothermal area (Werner \& Brantley 2003). In these areas $\mathrm{CO}_{2}$ generally emerges through a number of small, discrete emission points - in sedimentary basins these are commonly carbonated springs or mofettes (dry $\mathrm{CO}_{2}$ emission sites) but in hydrothermal areas they also include geysers and fumaroles. Individual flux measurements need to be treated with caution. Clearly the flux per unit area per unit time is not only dependent on the area over which the flux is averaged, but also it is not necessarily a good indicator of the risk to man; this is dependent on whether potentially harmful levels of $\mathrm{CO}_{2}$ can build up in the ambient air. Typical surface fluxes vary widely from $<5$ to localised values of $>17000 \mathrm{t} \mathrm{km}^{-2}$ day $^{-1}$. In all of these cases, human activity is more-or-less unaffected. The potential impact to ecosystems is currently being investigated at a number of sites.

The Rangely $\mathrm{CO}_{2}$ - EOR operation provides a good example of surface monitoring at a man-made $\mathrm{CO}_{2}$ injection site. Here, surface fluxes of deep-sourced $\mathrm{CO}_{2}$ are comparable with the lower limits of naturally occurring leaks, with no detectable environmental effects. However, it is likely that some, if not all, of this $\mathrm{CO}_{2}$ is microbially-oxidised methane rather than injected $\mathrm{CO}_{2}$ leaking from the reservoir 
(Klusman 2003). No leakage has currently been detected at the Weyburn CO2-EOR project (Wilson \& Monea 2004).

A putative future storage site with $500 \mathrm{Mt}$ of $\mathrm{CO}_{2}$ stored may, depending on subsurface structure, have a storage footprint in the region of $100 \mathrm{~km}^{2}$. An annual leakage rate of $0.01 \%$ (the Hepple \& Benson $550 \mathrm{ppm}$ performance criterion) would give rise to surface fluxes peaking at $50 \mathrm{kt}$ per year or $\sim 137$ tonnes per day. If leakage were distributed uniformly over the storage footprint, surface fluxes would be between 1 and 2 tonnes $\mathrm{km}^{-2}$ day $^{-1}$, much lower than many non-hazardous natural leaks. On the other hand, if leakage were concentrated along a fault, say $5 \mathrm{~km}$ long with a permeable damage zone $20 \mathrm{~m}$ wide, then the surface flux might approach 1400 tonnes $\mathrm{km}^{-2}$ day $^{-1}$. This is similar to fluxes found in naturally-occurring leakage sites and is a more typical leakage scenario. Evidence from natural $\mathrm{CO}_{2}$ mofettes suggest that gases leaking from depth rarely have a large uniform distribution, since once breakthrough is achieved in a small area this becomes the effective pathway for migration.

Furthermore, the degree to which a given leakage flux will be hazardous depends on a large number of factors, including surface topography and infrastructure, weather conditions, population density and the nature of surface terrestrial or marine ecosystems (West et al. 2005). In general the risk depends more on how effectively the emitted $\mathrm{CO}_{2}$ is dispersed than on the quantity released (Hepple 2005).

The key issue in shallow monitoring both for hazardous leakage and also for emissions performance is how to monitor a large potential leakage area robustly. One approach would be to identify the most likely leakage zones (from other information such as the presence of faults, old wells etc) and concentrate monitoring around them. This depends on reliable prediction however. Another approach would be to concentrate monitoring on those areas where leakage would have the greatest potential impact (e.g. built-up areas in structural depressions). A third approach would be to carry out systematic stochastic atmospheric monitoring of the whole potential leakage area, integrated with more detailed localised monitoring focussed on detected atmospheric anomalies, though the risks for false positive anomalies in built-up or industrial areas could be high. Clearly the strategy for leakage monitoring is likely to be highly site specific, and will depend on the type and reliability of site information, information from deep monitoring, overall risk assessments, and potential impacts.

\section{Towards a pragmatic monitoring programme for long term assurance}

As stated above, a properly selected site should have a secure geological seal or seals which, providing performance goes according to plan, should store $\mathrm{CO}_{2}$ indefinitely (far in excess of the atmospheric requirements). Within these seals specific containment risks may be identified, such as wellbores or faults. Estimating potential leakage through such containment risks depends on assessing the probability of their failure and also on some kind of flux estimation based on flow simulation. Both of these parameters are exceedingly poorly-constrained however, and to all intents and purposes it is not currently possible to reliably predict, in a quantitative way, future site leakage performance for geological storage. 
An effective site monitoring programme therefore needs to address aspects of site performance in a pragmatic rather than a prescriptive way (see also Pearce et al. 2006). The main objectives of monitoring might be as listed below:

- To demonstrate that the site is currently performing effectively (perhaps with respect to a stated emissions criterion) and safely.

- To track storage performance with respect to the containment risks and enable suitable remediation if necessary.

- To calibrate and verify predictive models of future storage site behaviour to permit satisfactory site closure.

- To provide warning of any future hazardous surface leakage.

- To identify and measure surface leakage should it occur.

These will probably require deep geophysical and/or well monitoring systems focussed on the primary storage reservoir and caprock, and also shallow subsurface, surface and atmospheric detection systems and baseline datasets. The above highlevel objectives translate to a number of specific technical aims, these include:

- Direct imaging (and, if possible, quantification) of $\mathrm{CO}_{2}$ in the storage reservoir.

- Measurement of pressure changes in and around the reservoir.

- Detection of migration of $\mathrm{CO}_{2}$ from the primary reservoir.

- Detection of migration of $\mathrm{CO}_{2}$ through the overburden to shallower depths.

- Detection and/or measurement of $\mathrm{CO}_{2}$ at the surface or in the atmosphere or water-column.

In addition to the overall aims and objectives, monitoring tool selection depends on a number of site specific factors including surface conditions (onshore/offshore, rural, urban, flat mountainous etc), site geology (reservoir depth, type etc). The International Energy Authority Greenhouse Gas Programme website hosts an interactive tool for the design of $\mathrm{CO}_{2}$ monitoring programmes (IEA 2007). This allows the user to input basic storage site parameters (location / land-use, reservoir depth, reservoir type, injection quantity), and up to ten monitoring aims. It then calculates applicability scores for specific monitoring technologies according to the selected aims. These are based on the expected technical capability of the various tools for the given site, but cost considerations will inevitably have a part to play too. Thus it may be cost-effective to deploy a number of complementary monitoring tools rather than adhere strictly to a technically optimal monitoring programme. An example of this would be an onshore storage case where the repeat interval for timelapse seismic monitoring may be relaxed by deploying intermediate gravimetry surveys at much lower expense. Such strategies will be very site-specific. Thus, for offshore storage, gravimetry is comparably expensive to 3D seismic, so would not 
generally constitute an effective cost-saving option except perhaps where it provided important complementary data, such as at Sleipner (see above).

Ultimately the selected monitoring programme depends on the monitoring aims, which are highly site-specific. It is for the site operator and the regulator to agree on these, and on a cost-effective suite of tools to achieve them. In general terms, for a site performing according to expectations, the repeat frequency of monitoring surveys would decrease with time, as confidence in predictive in models grows - particularly during the post-injection phase.

\section{Conclusions}

Site monitoring will play a key role in future large-scale $\mathrm{CO}_{2}$ storage operations. Deep-focussed methods will be used to prove short-term site compliance with regulatory requirements, to remediate non-compliances should they occur, and to constrain and steer simulations of longer-term site performance. At present, uncertainty in geophysical parameters and fine-scale fluid flow processes preclude accurate quantification of $\mathrm{CO}_{2}$ in the subsurface. Nevertheless, by adopting a multistrand approach, utilising complementary tools, and coupling results to flow simulations, uncertainties continue to be reduced. With shallow-focussed methods the aims are to establish pre-injection baseline conditions and to develop effective methods of detecting and monitoring surface leaks if and when they occur.

Assessment of site performance depends on the parameter under consideration. Safety performance is highly site specific, depending on subsurface migration paths, surface leakage fluxes and how these interact with surface infrastructure and biota. Emissions performance can be more easily generalised. A simple published criterion for emissions performance can be tested at current storage sites. Results so far analysed suggest that Sleipner is meeting or exceeding this criterion.

Specific monitoring programmes will clearly vary from site to site, depending firstly on geology but also on surface conditions - whether the site is offshore or onshore, beneath an urban or rural situation etc. As more monitoring data becomes available from large-scale storage sites, both onshore and offshore, it will become clearer how optimal site monitoring strategies can be developed. Although not discussed in detail here, it is clearly desirable that site monitoring activities are cost-effective, such that the total monitoring costs comprise just a small fraction of the total capture and storage budget. To achieve these aims it is likely that a range of different tools will be deployed, which may change as the project develops, utilised in a complementary manner to maximise information content whilst at the same time, minimising overall costs.

\section{Acknowledgements}

We thank the CO2STORE consortium for permission to use the Sleipner data in this work. CO2STORE is funded by the EU by industry partners Statoil, BP, Exxon, Norsk Hydro, Schlumberger,Total and Vattenfall, and by national governments. R\&D partners are BGR (Budesanstalt fur Geowissenschaften und Rohstoffe), BGS (British Geological Survey), BRGM (Bureau de Recherches Geologiques et Minieres), GEUS 
(Geological Survey of Denmark), IFP (Institute Francais du Petrole), NGU

(Norwegian Geological Survey), TNO-NITG (Netherlands Institute of Applied

Geoscience - National Geological Survey) and SINTEF Petroleum Research. Special thanks are due to the UK DTI for funding much of the generic monitoring work. The paper benefited from perceptive and detailed reviews by Stefan Bachu and Malcolm Wilson. Permission to publish is given by the Executive Director, British Geological Survey (NERC). 


\begin{tabular}{|c|c|c|}
\hline $\begin{array}{c}\text { Stabilization } \\
\text { target }(\mathrm{ppm})\end{array}$ & $\begin{array}{c}\text { Steady-state allowable } \\
\text { emissions }\left(\mathrm{GtCO}_{2} \mathrm{yr}^{-1}\right)\end{array}$ & $\begin{array}{c}\text { Allowable leakage } \\
\left(\% \mathrm{yr}^{-1}\right)\end{array}$ \\
\hline & & \\
\hline 350 & 3.3 & 0.01 \\
\hline 450 & 7.0 & 0.01 \\
\hline 550 & 9.9 & 0.01 \\
\hline 650 & 12.8 & 0.1 \\
\hline 750 & 15.8 & 0.1 \\
\hline
\end{tabular}

Table 1: Allowable steady state emissions, from Hepple and Benson (2003) 


\begin{tabular}{|r|c|c|}
\hline & Area $\left(\mathrm{km}^{2}\right)$ & $\begin{array}{c}\text { Flux (tonnes } \mathrm{km}^{-2} \\
\left.\text { day }^{-1}\right)\end{array}$ \\
\hline Tyrrhenian Basin & 15 & $\sim 5$ \\
\hline Matraderecske & & $\sim 300$ \\
\hline Matraderecske faults & & $\sim 17000$ \\
\hline Alban hills & & $\sim 2570$ \\
\hline Yellowstone & 4500 & $\sim 10$ \\
\hline Rangeley EOR & 78 & $\sim 0.3$ \\
\hline
\end{tabular}

Table 2: Estimated leakage from natural $\mathrm{CO}_{2}$ occurrences and deep-sourced $\mathrm{CO}_{2}$ fluxes from the Rangeley CO2-EOR site 


\section{REFERENCES}

Angerer, E., Crampin, S., Li, X.Y. \& DAVIS, T.L. 2002. Processing, modelling and predicting timelapse effects of over-pressured fluid-injection in a fractured reservoir, Geophysical Journal International, 149, 267 - 280.

Arts, R., Eiken, O., ChAdwick, R.A., Zweigel, P., VAn Der MEer, L. \& Zinszner, B. 2004 a. Monitoring of $\mathrm{CO}_{2}$ injected at Sleipner using time-lapse seismic data. Energy, 29, 1383-1393. Elsevier Science Ltd, Oxford, UK.

Arts, R., Eiken, O., Chadwick, R.A., Zweigel, P., VAn Der Meer, L. \& Kirby, G.A. 2004b. Seismic monitoring at the Sleipner underground $\mathrm{CO}_{2}$ storage site (North Sea). In: BAINES, S., GALE, J. \& WORDEN, R.J. (eds) Geological Storage for $\mathrm{CO}_{2}$ emissions reduction. Special Publication of the Geological Society, London, 233, 181 - 191.

ARTS, R., CHADWICK, R.A. \& EIKEN, O. 2005. Recent time-lapse seismic data show no indication of leakage at the Sleipner CO2 injection site. In: RuBIN, E.S., KEITH, D.W. \& GILBOY, C.F. (eds) Proceedings of the $7^{\text {th }}$ International Conference on Greenhouse Gas Control Technologies. Volume I, Elsevier, Oxford, $653-660$.

BAINES, S.J \& WORDEN, R.H. 2001. Geological $\mathrm{CO}_{2}$ disposal: understanding the long term fate of $\mathrm{CO}_{2}$ in naturally occurring accumulations. In: Williams, D., DuRIE, B., MCMullan, P., PAulson, C. \& Smith, A. (eds). Proceedings of the $5^{\text {th }}$ International Conference on Greenhouse Gas Control Technologies, Collingwood, Australia: CSIRO, 311 - 316.

BAKlid, A., KorbøL, R. \& Owren, G. 1996. Sleipner Vest $\mathrm{CO}_{2}$ disposal, $\mathrm{CO}_{2}$ injection into a shallow underground aquifer. SPE Annual Technical Conference and Exhibition, Denver, Colorado, USA, SPE paper 36600, 1-9.

Benson, S.M., GASPERIKova, E. \& Hoversten, M. 2004. Overview of Monitoring Techniques and Protocols for Geologic Storage Projects. IEA Report Number PH4/29.

Chadwick, R.A., ArTs, R., EIKEn, O., Kirby, G.A., LindeBerg, E. \& ZwEIGEL, P. 2004. 4D seismic imaging of an injected $\mathrm{CO}_{2}$ bubble at the Sleipner Field, central North Sea. In: DAVIES, R.J., CARTWRight, J.A., STEWART, S.A., LAPPIn, M. \& UnDERHILl, J.R. (eds) 3-D Seismic Technology: Application to the Exploration of Sedimentary Basins. Geological Society, London, Memoirs, 29, 305314.

CHADWICK, R.A., ARTS, R. \& EIKEN, O. 2005. 4D seismic quantification of a growing $\mathrm{CO}_{2}$ plume at Sleipner, North Sea. In: Dore, A.G. \& VINING, B. (eds) Petroleum Geology: North West Europe and Global Perspectives - Proceedings of the $6^{\text {th }}$ Petroleum Geology Conference. Petroleum Geology Conferences Ltd. Published by the Geological Society, London, 1385 - 1399.

DTI. 2005. Monitoring Technologies for the Geological Storage of $\mathrm{CO}_{2}$. Technology Status Report DTI/Pub URN 05/1032. Crown copyright, London, UK.

Goff, F., Love, S.P., WArren, R.G., Counce, D., Obenholzner, J., Siebe, C. \& SchmidT, S.C. 2001. Passive infrared remote sensing evidence for large, intermittent $\mathrm{CO}_{2}$ emissions at Popocatepetl volcano, Mexico. Chemical Geology, 177, 133-156.

HePPLE, R.P. 2005. Human Health and Ecological Effects of Carbon Dioxide Exposure. In: BENSON, S.M. (ed.) Carbon Dioxide Capture for Storage in Deep Geologic Formations - Results from the $\mathrm{CO}_{2}$ Capture Project, Volume 2, Elsevier Ltd, Oxford, UK, 1143-1172.

HEPPLE, R.P. \& BENSON, S.M. 2003. Implications of surface seepage on the effectiveness of geological storage of carbon dioxide as a climate change mitigation option. In: Gale, J. \& Kaya, Y. (eds) Greenhouse Gas Control Technologies, Volume 1, Elsevier Science Ltd, Oxford, UK, 261-266. 
Hoversten, G.M., GritTo, R., DALey, T.M., MAJer, E.L. \& Myer, L. 2002. Crosswell seismic and electromagnetic monitoring of $\mathrm{CO}_{2}$ sequestration. In: Gale, J. \& Kaya, I. (eds) Greenhouse Gas Control Technologies. Elsevier Science Ltd, Oxford, UK, 371 - 376.

IEA. 2007. Monitoring Selection Tool - Interactive Design of Monitoring Programmes for the Geological Storage of $\mathrm{CO}_{2}$.

WorldWide Web Address: http://www.co2captureandstorage.info/co2monitoringtool/

Johansen, S., Amundsen, H.E.F., Røsten, T., Ellingsrud, S., Eidesmo, T. \& Bhuyian, A.H. 2005. Subsurface hydrocarbons detected by electromagnetic sounding. The First Break, 23, 31-26.

Kikuta, K., Hongo, S., TANASE, D. \& OHSumi, T. 2005. Field test of $\mathrm{CO}_{2}$ injection in Nagaoka, Japan. In: Wilson, M., MorRis, T., Gale, J. \& Thambimuthu, K. (eds): Proceedings of the $7^{\text {th }}$ International Conference on Greenhouse Gas Control Technologies. Volume II/1. Elsevier Science Ltd, Oxford, UK, $1367-1372$.

KLUSMAN, R.W., 2003. A geochemical perspective and assessment of leakage potential for a mature carbon dioxide enhanced oil recovery project as a prototype for carbon dioxide sequestration: Rangely field, Colorado. Bulletin of the American Association of Petroleum Geologists, 87, 1485-1507.

KorbøL, R. \& KadDOUR, A. 1995. Sleipner Vest $\mathrm{CO}_{2}$ disposal - injection of removed $\mathrm{CO}_{2}$ into the Utsira Formation. Energy Conversion and Management, 36, 509-512.

Lindeberg, E., Zweigel, P., Bergmo, P., Ghaderi, A. \& Lothe, A. 2001. Prediction of $\mathrm{CO}_{2}$ distribution pattern improved by geology and reservoir simulation and verified by time lapse seismic. In: Williams D., Durie, B., McMullan, P., Paulson, C. \& Smith, A. (eds) Proceedings of the $5^{\text {th }}$ International Conference on Greenhouse Gas Control Technologies, CSIRO, Collingwood, Australia, $372-377$

LINDEBERG, E. 2003. The quality of a $\mathrm{CO}_{2}$ repository: What is the sufficient retention time of $\mathrm{CO}_{2}$ stored underground. In: GALE, J. \& KAYA, Y. (eds) Greenhouse Gas Control Technologies, Volume 1, Elsevier Science Ltd, Oxford, UK, 255 - 260.

McKenna, J., Gurevich, B., Urosevic, M. \& Evans, B.J. 2003. Rock physics - application to geological storage of $\mathrm{CO}_{2}$. Journal of the Australian Petroleum Production and Exploration Association, 43, 567-576.

MAVKO, G. \& MuKERJI, T. 1998. Bounds on low frequency seismic velocities in partially saturated rocks. Geophysics, 63, 918-924.

Metz, B., DAvidson, O., ConinCK, H. DE, LoOs, M. \& Meyer, L. (eds) 2005. IPCC Special Report on Carbon Capture and Storage. Cambridge University Press, New York.

Miles N.L., DAVIS, K.J. \& WYNGAARD, J.C. 2004. Detecting leaks from below ground $\mathrm{CO}_{2}$ reservoirs using eddy covariance. In: BEnson, S.M. (ed.) Carbon Dioxide Capture for Storage in Deep Geologic Formations - Results from the $\mathrm{CO}_{2}$ Capture Project, Volume 2, Elsevier Ltd, Oxford, UK, 1031 1044.

Mori, T., Hernandez, P.A., SAlazAr, J.M.L, Perez, N.M., NotSu, K. 2001. An in situ method for measuring $\mathrm{CO}_{2}$ flux from volcanic-hydrothermal fumaroles. Chemical Geology, 177, pages 85-99.

MYer, L.R., Hoversten, G.M \& GASPERIKOVA, E. 2002. Sensitivity and cost of monitoring geologic sequestration using geophysics. In: GALE, J. \& KAYA, I. (eds.) Greenhouse Gas Control Technologies. Elsevier Science Ltd, Oxford, UK, 377 - 382.

NAKICENOVIC, N. \& SWART, R. (eds) 2000. Special report on emission scenarios (SRES). Intergovernmental Panel on Climate Change (IPCC), Cambridge University Press, New York, 599 pages.

Nooner, S., Zumberge, M., Eiken, O., Stenvold, T. \& Thibeau, S. 2006. Constraining the density of $\mathrm{CO}_{2}$ within the Utsira formation using time-lapse gravity measurements. Proceedings of the 8th 
International Conference on Greenhouse Gas Control Technologies, Trondheim, Norway, 19-22 June, 2006. ISBN: 0-08-046407-6, Elsevier, published on CD.

Pearce, J., Chadwick, R.A., Holloway, S. Kirby, G.A. 2006. The objectives and design of generic monitoring protocols for $\mathrm{CO} 2$ storage. Proceedings of the 8th International Conference on Greenhouse Gas Control Technologies, Trondheim, Norway, 19-22 June, 2006, ISBN: 0-08-046407-6, Elsevier, published on $\mathrm{CD}$.

Pickles, W.L. \& Cover, W.A. 2004. Hyperspectral Geobotanical Remote Sensing for $\mathrm{CO}_{2}$ Storage Monitoring. In: Benson, S.M. (ed) Carbon Dioxide Capture for Storage in Deep Geologic Formations - Results from the $\mathrm{CO}_{2}$ Capture Project, Volume 2, Elsevier Ltd, Oxford, UK, 804 - 858.

SChellnhuber, J.H. (ed) 2006. Avoiding Dangerous Climate Change. Cambridge University Press, Cambridge, UK.

SENGUPTA, M. \& MAVKO, G. 2003. Impact of flow-simulaiton parameters on saturation scales and seismic velocity. Geophysics, $68,1267-1280$.

Shipton, Z. K., Evans, J.P., Dockrill, B., Heath, J.M., Williams, A., Kirchner, D. \& Kolesar, P.T. 2005. Natural leaking $\mathrm{CO}_{2}$-charged systems as analogs for failed geologic storage reservoirs. 695708. In: BENSON, S.M. (ed) Carbon Dioxide Capture for Storage in Deep Geologic Formations Results from the CO2 Capture Project, Volume 2, Elsevier Ltd, Oxford, UK, 699-712.

Strutt, M. H., Beaubien, S. E., Baubron, J. C., Brach, M., CARdellini, C., Granieri, R., Jones, D. G., Lombardi, S., PenNer, L., QuATtrocchi, F. \& Voltatorni, N. 2003. Soil gas as a monitoring tool of deep geological sequestration of carbon dioxide: preliminary results from the EnCana EOR project in Weyburn, Saskatchewan (Canada). In: GALE, J. \& KAYA, Y. (eds) Greenhouse Gas Control Technologies, Volume I. Elsevier Science Limited, Oxford, 391-396.

Welles, J.M., DEMETRIADES-ShAH, T.H. \& MCDERMitT, D.K. 2001 Considerations for measuring ground $\mathrm{CO}_{2}$ effluxes with chambers. Chemical Geology, 177 (1-2), 3-13.

WeRneR, C. \& BRANTLEY, S. 2003. $\mathrm{CO}_{2}$ emissions from the Yellowstone volcanic system. Geochemistry Geophysics Geosystems, 4 (7), 1061.

West, J.M., PeARCE, J.M., Bentham. M. \& MAUL, P.R. 2005. Environmental Issues and the geological Storage of $\mathrm{CO}_{2}$ - a discussion document. European Environment, 15, 250-259.

WigLEY, T.M.L., Richels, R. \& EDMONDS, J.A. 1996 Economic and environmental choices in the stabilization of atmospheric CO2 concentrations. Nature, 379, 240-243

WiLson, M. \& MoneA, M. 2004. IEA GHG Weyburn $\mathrm{CO}_{2}$ Monitoring \& Storage Operation Summary Report 2000 - 2004. Petroleum Technology Research Centre, Regina, SK, Canada. 


\section{Figure captions}

Fig. 1 Schematic diagram of an underground $\mathrm{CO}_{2}$ storage site showing possible migration and leakage pathways and monitoring options. N.B storage topseal need not necessarily be salt.

Fig. 2 Potential tools for monitoring $\mathrm{CO}_{2}$ storage

Fig. 3 Part of the 1999 3D seismic dataset from Sleipner. The front left-hand corner of the cube intersects the $\mathrm{CO}_{2}$ plume, imaged as a number of bright, sub-horizontal seismic reflections.

Fig. 4 Gravity models to illustrate changes in gravimetric signature caused by migration of $5 \mathrm{Mt}$ of $\mathrm{CO}_{2}$ from the primary storage reservoir to shallower depth

Fig. 5 a) Multibeam sonar image of the seabed showing pockmarks and other features associated with natural gas leakage at the seabed b) High resolution acoustic profile showing (methane) gas plumes in the water column (courtesy of B. Schroot).

Fig. 6. Time-lapse seismic images of the $\mathrm{CO}_{2}$ plume a) N-S inline through the 1994 dataset prior to injection and through the 1999, 2001 and 2002 datasets. Enhanced amplitude display with red/yellow denoting a negative reflection coefficient. b) Maps of integrated absolute reflection amplitudes calculated in a two-way travel-time (twtt) window from 0.8 to 1.08s, for 1994, 1999 and 2001. Blue - low reflectivity; red - high reflectivity. Black disc denotes injection point.

Fig. 7. Velocity pushdown. a) Inline through the storage reservoir in 1994 and 1999 showing pushdown of the Base Utsira Sand (the reservoir) beneath the plume. b) Cross-correlogram of a reflection window beneath the central part of the 2001 plume. Yellow line follows the correlation peak and defines the pushdown. c) Pushdown maps in 1999 and 2001. Black disc denotes injection point.

Fig. 8 3D seismic modelling of the Sleipner $\mathrm{CO}_{2}$ plume: Acoustic impedance model based on reservoir flow simulation (left) and synthetic seismic volume (right).

Fig. 9 2D inverse modelling of the 1999 plume. Observed data (centre) compared with synthetic seismograms based on inverse models for two plume scenarios: Injection point at $36^{\circ} \mathrm{C}$ with fine-scale mixing throughout (left); Injection Point at $45^{\circ}$ $\mathrm{C}$ with patchy mixing in the intra-layer dispersed component of $\mathrm{CO}_{2}$ (right).

Fig. 10 Estimating the detection limits for small amounts of $\mathrm{CO}_{2}$. a) Map of the 199994 difference data showing integrated reflection amplitude in a 20 ms window centred on the top Utsira Sand. Note high amplitudes corresponding to two small $\mathrm{CO}_{2}$ accumulations at the top of the reservoir. Note also scattered amplitudes due to repeatability noise. b) Seismic line showing the topmost part of the plume and the two topmost accumulations. 
Fig. 11 Sleipner gravity survey a) ROV with gravimeter at left b) map of gravity station coverage 


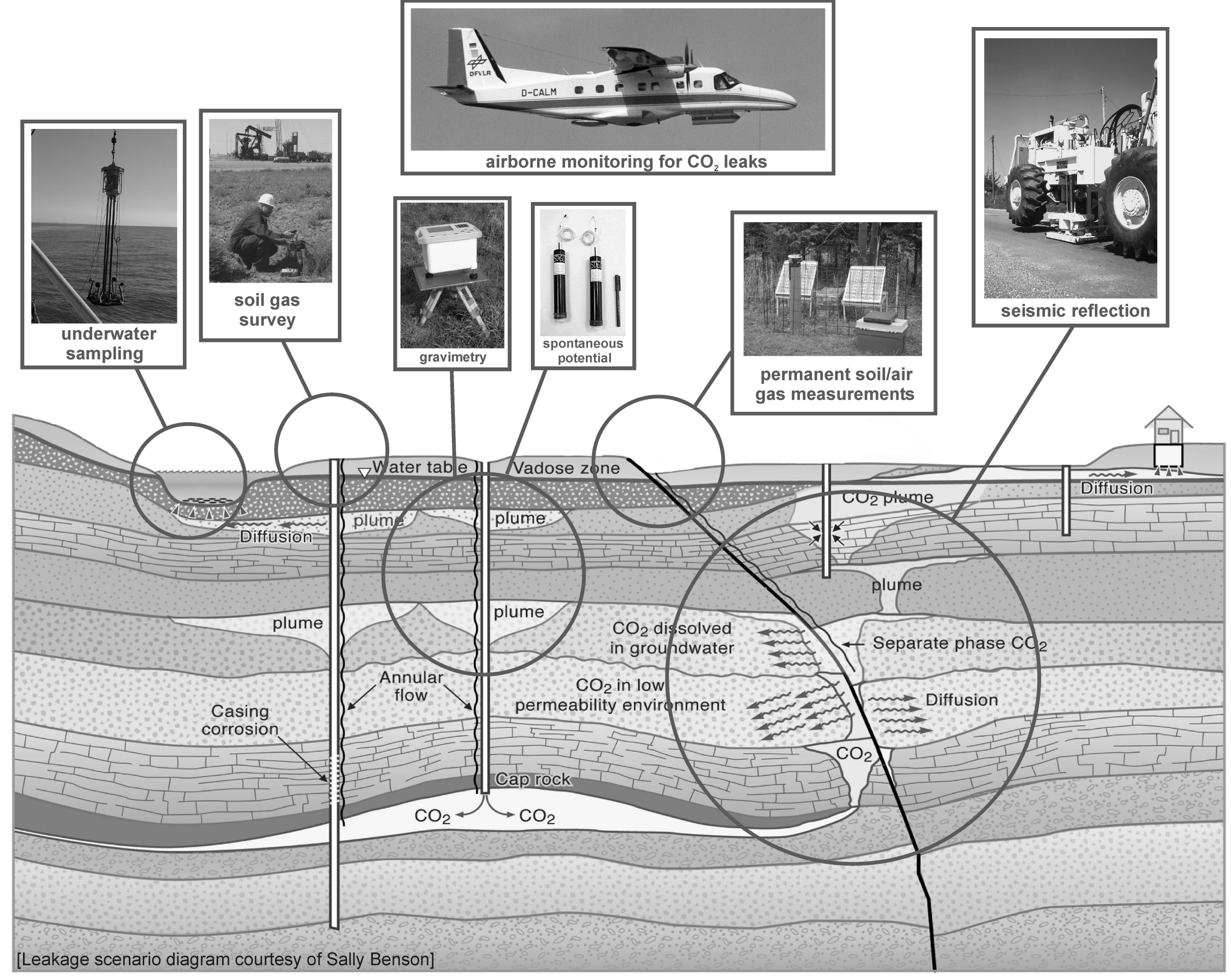




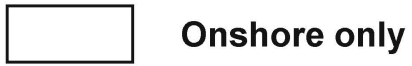

Offshore only

Onshore \& Offshore

Seismic

3D/3C surface seismic

2D surface seismic

Boomer / Sparker

High resolution acoustic imaging

Microseismic monitoring

cross-hole seismic

VSP

Sonar Bathymetry

Sidescan sonar

Gravimetry

Multi beam echo sounding

Time lapse surface gravimetry

Time lapse well gravimetry

Surface EM

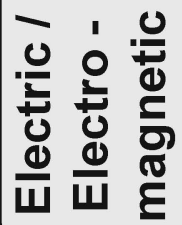

Seabottom EM

Cross-hole EM

Permanent borehole EM

Cross-hole ERT

ESP

Downhole fluid chemistry

PH measurements

Tracers

Seawater chemistry

Bubble stream chemistry

Non dispersive IR gas analysers

IR diode lasers

Gases

on

Mobile gas cells

Eddy covariance

Gas flux

soil

Gas concentrations

Ecosystems studies

Airborne hyperspectral imaging

Satellite interferometry

Airborne EM

Airborne spectroscopy

Geophysical logs

Pressure / temperature

Tiltmeters 


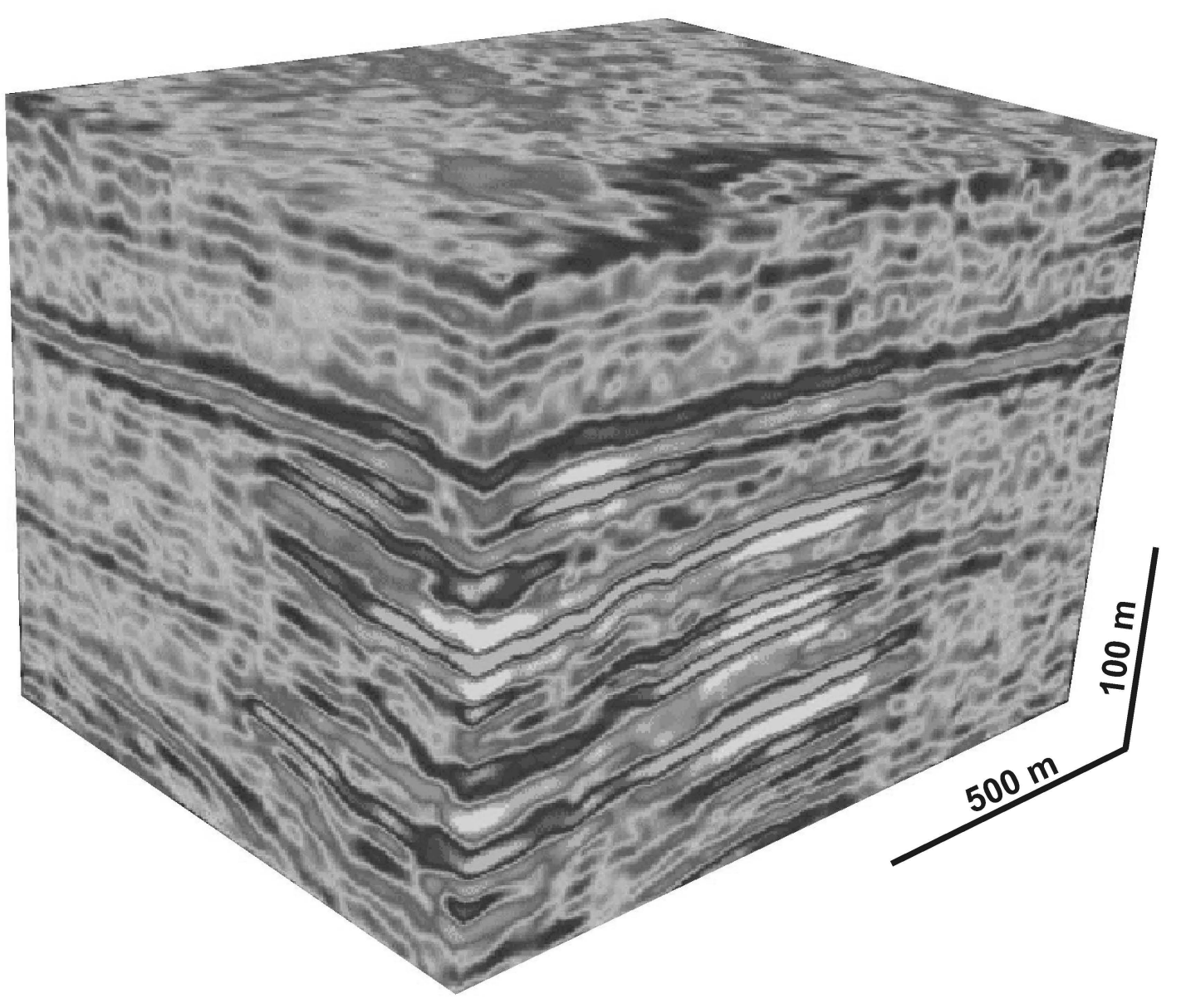




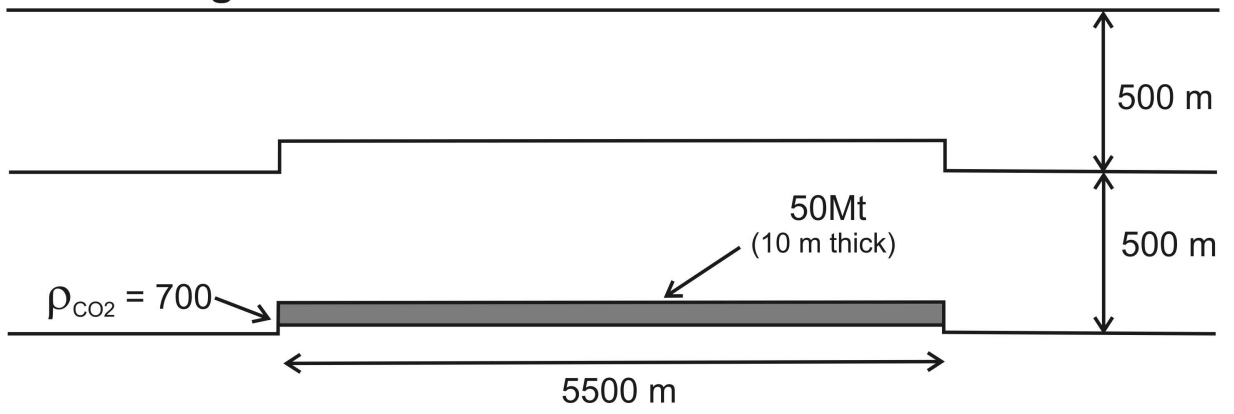

\section{After migration}

$\rho_{\mathrm{CO} 2}=700$

\section{Gravity signature}

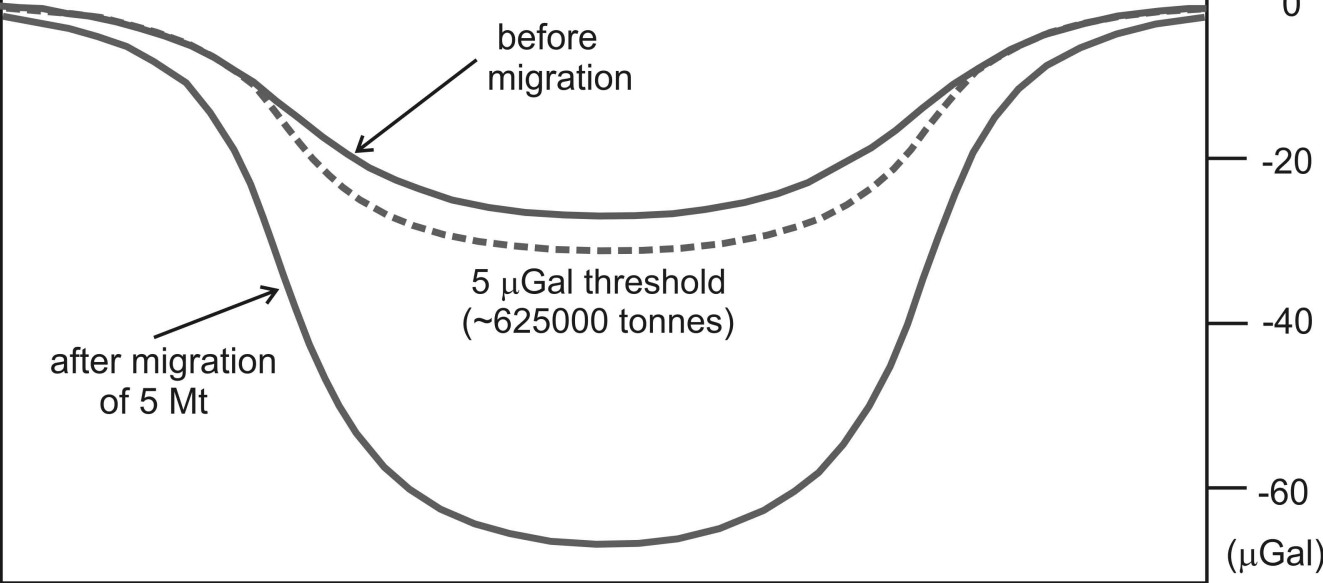




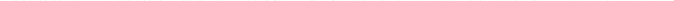




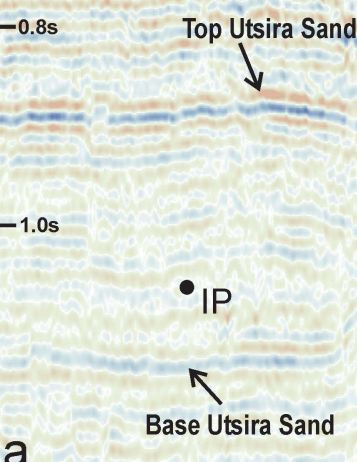

a

Base Utsira Sand

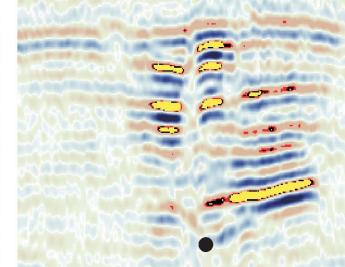

1999

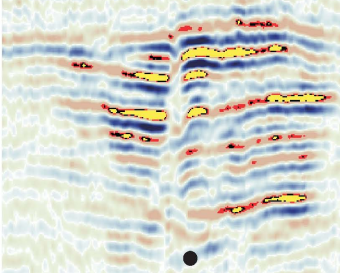

2001

$500 \mathrm{~m}$

2002

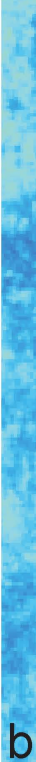

1994

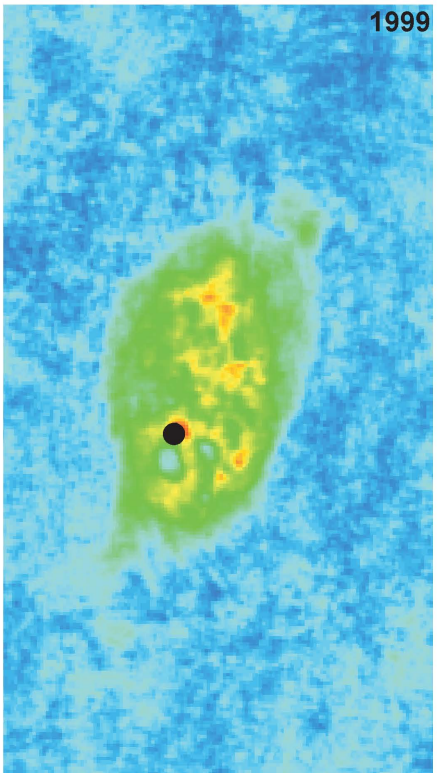

2001

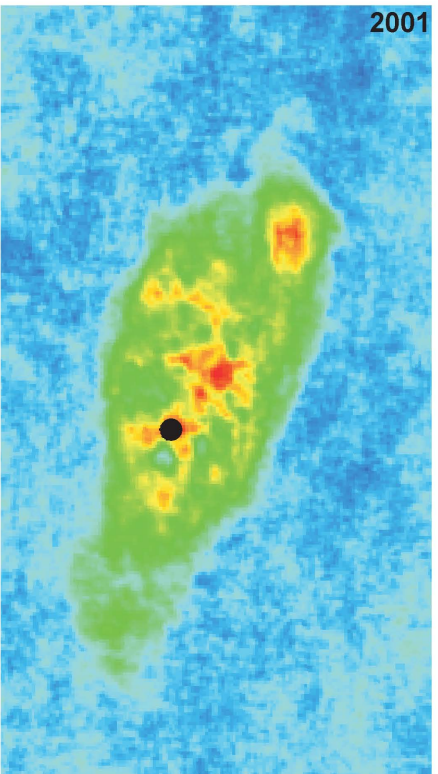

$500 \mathrm{~m}$ 


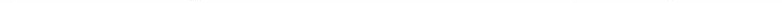



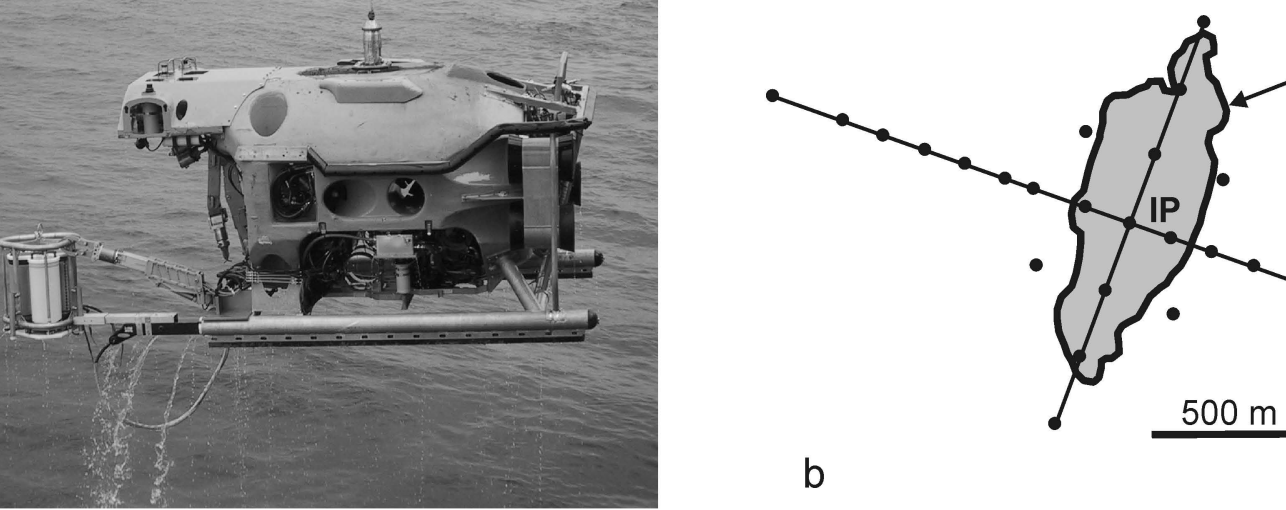

size of $\mathrm{CO}_{2}$ plume in 2001

b 